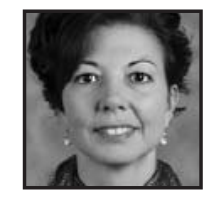

\title{
Democracies in Action: A Changing Learning Community Landscape
}

\author{
Carol A. Mullen, The University of North Carolina at Greensboro
}

\begin{abstract}
Learning alongside others to effect transformation of community and self is a process of inquiry that guides theory and practice. My purpose as an author is to portray a balanced, realistic portrait of the promises and pitfalls of engaging in professional learning communities (PLCs). Herein I present the results of a democratic project that united 42 scholars and practitioners who made discoveries as collaborators within evolving communities of practice geared toward desirable change. I also draw upon the relevant literature to describe this trend and identify possibilities for renewal, reflection, and inquiry that arise out of PLCs.
\end{abstract}

$\mathrm{n}$ this essay, I advance the idea and practice of learning community as democracy in action. My purpose as an author is to portray a balanced, realistic portrait of the promises and pitfalls of engaging in professional learning communities (PLCs). To undertake this task, I build on the relevant literature, including synthesized results from my collaborative, multi-site case study described in The Handbook of Leadership and Professional Learning Communities (Mullen, 2009). The 2009 project drew together 42 scholars and practitioners from schools, universities, and institutes across the United States to analyze their work in communities of practice geared toward desirable change. After exploring this multifaceted learning innovation from different perspectives and at numerous sites, it was confirmed for us that learning community is indeed a promising democratic reform deserving further study. The scholars and practitioners who contributed to this project wrote from organizational, cultural, technological, and mentoring perspectives that incorporate cultural considerations. My intended audience is education practitioners in particular as well as 
scholars for whom learning as a school community is essential and for whom important ideas are translated here into strategies.

My perspective about PLCs as democratic learning communities is consistent with a view of democracy as a change process committed to principles of freedom and responsibility that people use to shape their work (Giroux, 1992). Democratic community building enables members to collectively change who they are, fully participate in their work lives, socially negotiate meaning in expansive ways (Wenger, 1998), and operationalize their individual and collective rights (Jenlink \& Jenlink, 2008). Committed leaders persevere as agents of change and renewal, no matter how encumbered mandated reforms might make them feel.

Based on my experiences with learning communities over the years, I believe that the PLC is, at least ideally, a type of democracy in action. An established approach for organizing the professional development of educators, the PLC is a popular form of practice-based research (Birchak et al., 1998; Donahoo \& Hunter, 2007). While collaborative professional learning is not new, the social justice bent on learning community and the practicality of developing communities that are democratic, authentic, and sustained remains challenging. Educators can benefit from learning about the inner workings of PLCs and making concrete contributions to them. Through such work, we can re-imagine our learning landscapes and role in forging collective action that strengthens, even transforms, our relationships and communities.

\section{Learning Community Landscapes and Frameworks}

PLCs integrate two traditionally distinct concepts-professional learning and community. In this model, the professional's expert knowledge and focus on student learning and needs are combined with the community's shared interests, core values, and mutual responsibility, but the PLC can be defined in different ways (Mullen, 2009). For example, the PLC can be viewed as a model of school organization designed to foster collaboration and continuous learning among educators for facilitating school improvement. Further, the PLC model has become a popular means for promoting organizational, cultural, and relational change through shared purposes (Birchak et al., 1998; Bullough \& Baugh, 2008; DuFour, 2004; Mullen \& Schunk, 2010). 
Principles that inform and guide the work of successful PLCs include commitment to change; shared vision and common goals; belief that all participants can effectively collaborate and contribute; encouragement of risk taking and sharing of ideas; use of research-based (leading, learning, and teaching) strategies; and design of assessments that reflect goals. Mullen and Schunk's (2010) meta-analysis of the learning communities research reveals that PLCs have leadership, organizational, and cultural goals and functions, and that the extent of the impact on teaching and learning in classrooms is only gradually emerging (Whitford \& Wood, 2010). Thus, a pitfall of PLCs is that benefits for student learning and success are often implicit or indirect.

Also deserving more attention is the potency of PLCs as a culture-changing process, not only as a strategy for school improvement. From this perspective, activist-oriented PLCs grapple with school inequities that Watts and Erevelles (2004) argue oppress many diverse children and youth, ranging from poverty to alienation, scapegoating, and bullying, for which they call for empowering alternatives. The PLC initiative is one such alternative through which whole-school change can occur. Such groups may establish counter-normative goals (e.g., culturally responsive learning) and members may be facilitated to deliberate in ways that productively surface biases and emotions (Cooper, 2009). Decisions generated out of consensus-building dialogue can produce unifying actions. These include school campaigns and mottos (e.g., United for Change), policy creation, teacher modeling, customized courses (focused, e.g., on social skills), and assessment of (hostile and aggressive) behaviors. As a model of democracy in action, PLCs can foster cultural awareness for targeted education groups, such as students who alienate or hurt students they consider "different," as well as demographically changing schools.

PLCs are changing the learning landscape of schools, districts, and universities. Based on widespread and multifarious policies, implementations, and examples across North America, the PLC has potency as a strategy for educational change. Educators and policymakers concerned about school improvement have an invested interest in it as a staff development model. Stakeholder groups include teachers, teacher leaders, principals, often professors, and sometimes community members, state department personnel, intermediate service agency staff, district and campus administrators, superintendents, parents, and higher education administrators. Learning communities are in vogue as a vehicle for school-wide change and improvement (Dufour, 2004) and for student learning and engagement (Mullen \& Hutinger, 2008; Zhao \& Kuh, 2004). Perhaps the PLC initiative has reached the stature of being an educational movement, "sticking" as an idea that has staying power (Gladwell, 2002). 
The tipping point means something unusual or rare, such as Internet use or population patterns, has suddenly become the norm. A comparable vision for PLC models is for them to generate excitement and endure within the schooling culture in which they are initiated, having a lasting impact. Change happens slowly yet rapid change can emerge from seemingly slow progress. Applied to PLC networks, desirable outcomes with respect to practitioner collaboration, student learning, and organizational performance can suddenly spark, fundamentally changing a school. Shared leadership, partnership buy-in, synergy, reinforcement, and recognition are catalysts for changing negative cultures into democracies in action.

Conduits for creating PLCs are school-university partnerships, professional development schools, virtual learning communities (VLCs), and racially inclusive PLCs (Mullen, 2009). The 2009 project contributors engaged in a group learning process whereby they reflected on their own practice with a critical eye. The teacher groups they studied identified student learning needs and took action to meet those needs. PLCs can fruitfully undertake such potentially transformative practices as distributed leadership, collaborative inquiry, reflection, self-study, mentoring, coaching, and problem solving. All levels of leadership commit to improving student learning, enhancing faculty development, and enacting organizational change through supportive guidance, shared leadership, core values, collective learning, conducive conditions, and collaborative practice. PLCs, as self-study discourse communities, are the means and supporting structure for organizations to be continuously improved.

In the 2009 project, we collectively expressed a view of the PLC as a promising approach to educational change subsequent to having weighed the pros and cons of our various initiatives. Upon analyzing what we had together created, I appreciated more fully that PLC efforts range in the importance of the work attempted and accomplished within them, and in their degree of functionality and effectiveness, capacity for outreach, and circumference of inclusion. They also vary in the synergy generated and fulfillment of their promises. The belief that learning, teaching, and leading are inherently not only social but also democratic undergirds the PLC initiatives we described; moreover, our work is political, experimental, and unfinished.

Upon reflection, I also became convinced that the learning community literature, generally speaking, does not challenge the status quo in a significant way. The theoretical foundations upon which much of the research is based is presented as having functional value rather than a critical or an interpretive one. The literature includes populist writers, some of whom have been criticized for quick-fix, instrumental approaches and pre-packaged notions of "best practices" for developing and 
sustaining learning communities. In contrast, English (2008) invites practitioners to develop knowledge that is dynamic, collaborative, and creative, not standardized, and to develop their own promising practices. Next, I briefly describe four overriding perspectives (i.e., organizational, cultural, technological, and mentoring) that had relevance for the 2009 project contributors' work within democratically oriented PLCs.

\section{Organizational Perspective on Learning Community}

The organizational perspective of leadership and PLCs can be variable, dynamic, and diverse, just as it should be. In the 2009 project, we called for critical attention to this movement, attempting to rise to the occasion ourselves. Critique of school improvement reforms, including the PLC, was captured by such images as that of the zealot who "hops on" what is working organically in schools and reduces their potency by mandating reform through policy initiatives and other means. PLC development does not happen in a vacuum-instead, it is supported through a shared vision, purposeful agenda, and collective understanding of the change process. Researchers and practitioners alike have been cautioned to vigilantly monitor the bandwagon mentality encompassing the learning community innovation and the evangelical attitude toward it (Johnson \& Kruse, 2009). Ironically, those who are most directly involved in developing, implementing, and assessing PLCs are nonetheless affirming of PLC development as worthy. However, this initiative must be thoughtfully undertaken and must satisfy certain conditions.

Notably, organizationally minded change agents believe that the PLC initiative should be aligned with democratic aims and agendas that promote equity, inclusion, and success (Bullough \& Baugh, 2008, 2009). In addition, they know from firsthand experience that this intervention must yield organizational capacity and human capital for schools, districts, and universities. They also know that the ins and outs of a PLC developed organically feature a decentralized structure, partnership alliances, and teacher leadership focused on collaborative problem solving.

\section{Cultural Perspective on Learning Community}

Cultural writers encourage PLC members to democratize their community arrangements and group processes from the outset. Critical democratic groups are not just introspective-they are self-interrogating; they proactively adopt social justice stances, understand the dynamics of change, and recognize that learning communities are not automatically self-sustaining - instead, they require hard work, ongoing support, and personal commitment. As mentioned, culturally relevant 
education within demographically changing schools is an example of this practice in action (Cooper, 2009). Another manifestation focuses on aligning democratically practiced places of learning with the processes, resources, and activities necessary for transforming a school's social spaces (Jenlink \& Jenlink, 2008). Change agents must grapple with cultural diversity, difference, and inequality if they are to prepare teachers, students, and others to interface with a pluralistic constituency (English, 2008).

Institutions do not naturally awaken to the need for change, so activists must jump-start the process and propel it. Change agents bring integrity to the inner world of the self and the outer world in which they live as they create communities for learning and support (Clandinin, 2010). They re-imagine teaching and learning as a cooperative social and political practice enabled by active partnerships with constituents. In the 2009 project, while we reported cases and examples of partnership development within and across schools, universities, and institutes, we described a larger view of PLC development as environmental, cultural, and social. PLCs that transform outdated cultures renew education relative to their own buildings and the profession.

\section{Technological Perspective on Learning Community}

The technological perspective advances cultural ideas to inform thinking about new kinds of communities of practice. Geographically dispersed professionals participate in virtual learning as a community, endeavoring to foster their own development, establish shared purposes, and pursue new knowledge or skills through online communications (Lewis \& Allan, 2005). Educators use VLCs, often originated through conferences, courses, and workshops, to simulate real-life learning. Digital technology supports active learning, critical reflection, and collaborative inquiry (Mullen, 2009). Because it allows for online interaction and collaboration, some VLCs use Elluminate (http://www.elluminate.com). Pros and cons associated with this platform have been documented by a PLC group of leaders that renewed their professional organization and increased overall productivity by co-leading and co-learning within a computer-supported governance structure (Mullen, 2011). Pros included accelerated progress towards mutual goals and meeting convenience, and cons included a learning curve and technology glitches such as inaudible voice levels. Facilitators of VLCs use Web, audio, and/or video for engaging a community of learners in which members simultaneously talk and write questions and comments. Wenger's (1988) requirements of successful communities of practice, which are mutual engagement, joint enterprise, and shared repertoire, have been shown in numerous case experiments to have credibility (e.g., Lewis \& Allan, 2005; Mullen, 2011; Rogers, 2000). 
Systems thinkers create system-wide collaborative cultures among schools, universities, and outside agencies. PLCs are entities that are intrinsically linked from the classroom to the school and beyond. To this end, digital communication systems (e.g., high-speed digital networks) mobilize social, cross-institutional, and global networking (Mullen, 2011).VLCs are a widely disseminated example of how digital learning contexts can productively generate insight and action. Embedded within a social justice framework, this emergent practice encourages critical thought, human connection, open, honest dialogue, conflict resolution, and respect for difference (Cernohous, Wolsey, \& Grisham, 2010; Mullen, 2009).

Highly influential thinkers' (e.g., Jean Clandinin, John Dewey, Paulo Freire, Michael Fullan, John Goodlad, Nel Noddings, Thomas Sergiovanni) transformative ideas about education can be adapted to virtual and online learning. As frameworks undergirding goals, ideas from the education literature span such important concepts as community learning, grassroots activism, learning by doing, professional renewal, and teachers' professional knowledge. In the 2009 project, we discussed the frameworks that had guided our individual PLC initiatives. We expressed our belief that practitioners are social creatures whose cultivation of creative intelligence, selfhood, self-actualization, and activism depends on engagement in co-learning and coleading that is not left to chance. We also talked about how technology is not valuefree, as technology communications shape knowledge, power relations, and how we see the world and ourselves in it. Further, we used technology in the development of our PLCs - whether to augment face-to-face ( $\mathrm{f} 2 \mathrm{f}$ ) sessions or to outright foster VLCs. Moreover, we used a blended approach to create the 2009 project, meeting $\mathrm{f} 2 \mathrm{f}$ and online, and presenting at conferences.

\section{Mentoring Perspective on Learning Community}

Contributors to the 2009 project addressed collegial mentoring issues relevant to preservice teachers, beginning teachers, and inservice teachers. We approached activist mentoring in leadership and learning teams and as a peer-based community innovation. Intergenerational and cross-cultural relationships within PLC networks occur among teachers and administrators of different leadership styles, ages, generations, backgrounds, and ethnicities. A noteworthy benefit, mentoring-oriented PLCs foster cross-cultural and intergenerational understanding partly by including historically underrepresented groups (Davis, 2008). These provide a forum for teachers to influence school cultures through their own experiences of inquiry that generate peer-led communities, tight school-community linkages, deepened cultural awareness, and self-reflective citizens (McKenzie et al., 2008; Shields \& Mohan, 2008). 
Of additional benefit, the learning community arrangement provides opportunities for teacher leadership and participation through collaborating, coaching, and induction (Fives, Buehl, \& Myers, 2008). Mentoring cultures depend on such activities to turn places of work into flourishing learning communities. Formal induction programs can foster mentoring-based social networks for beginning teachers through which support, growth, and success are rewards. The 2009 project contributors explored underlying epistemological models of leadership (e.g., transactional, transformational, critical) and philosophies of education (action learning, culturally relevant knowledge, shared governance) that influence practitioners' work. They also described the catalytic role of administrators (e.g., principals) and teacher leaders (e.g., curriculum leaders) in team- and culture-building efforts.

\section{Challenges to Community Building and Breakthroughs}

Regrettably, many professionals work alone (Putnam, 2000). And yet, PLCs offer an invaluable source of social capital that leaders turn to when "build[ing] a coalition of support or sustain[ing] a position in times of conflict" (English, 2008, p. 27). A major goal of a democratic leadership is to develop and sustain networks that are relational, interactive, and mutually constructed and have egalitarian and humanistic aims (Cernohous et al., 2010; English, 2008; Wenger, 1998). Synergistic networks that support professional communities of collaboration yield benefits with respect to informational flow, reciprocal learning and bonding, collection action, and identity formation and solidarity.

The group mentality and identity within the PLC groups described by the project contributors (Mullen, 2009) worked in similar and different ways and within wide-ranging contexts. As differences, initiating agents were from schools, districts, universities, and institutes and the PLC networks reflected younger and more mature phases of development; the focus, engagement, and outcomes of them also varied significantly. As common themes, all the PLC group members included stakeholders from outside the school; they developed shared purposes connected to student learning and they studied their own learning processes.

For example, included in the 2009 project is a hallmark PLC group that teacher educator pioneer John Goodlad founded in 1986. The National Network for 
Educational Renewal is composed of over 20 school-university partnerships. Focused on renewal, not reform, of teacher education and schooling, the partners of these highly organized collaboratives have forged learning communities rooted in what is known as the Agenda for Education in a Democracy. Agenda developers of this multifaceted initiative, explicitly guided by Goodlad's philosophies, include the Institute for Educational Inquiry in Washington.

Researchers of this complex PLC model, a professor and superintendent (Bullough \& Baugh, 2009), describe the PLC networks' commitment to democratic schooling as a process of renewal through such means as internally self-initiated and experientially based work. One of these learning communities, the Brigham Young University (BYU)-Public School Partnership, organized in 1984, encompassed a school of education and five school districts totaling over 7,000 teachers, in addition to PLC subgroups (e.g., Associates Program, Principals' Academy, Leadership Preparation Program). Organized by this Partnership was a Goodlad-steeped curriculum that provided study, conversation, reflection, and inquiry on the shared purpose of democratic schooling and renewal. Groups of approximately 20 school and college educators met throughout the academic year to talk about research-based practices (they read over 20 books each year), and to participate in projects and activities.

More specifically, in the BYU Partnership's Alpine Associates program, 360 school practitioners (teachers and principals), including multidisciplinary university professors, deans, superintendents, and school board members, met up to six times yearly. They participated in daylong retreats and an annual conference to experience collaboration across educational roles, discuss salient issues anchored in readings, and decide future directions for their work. Surveys conducted within the groups revealed the need for teacher leadership and explicit connections to student learning through analysis of diverse data, in addition to the fostering of school cultures.

The PLC members experienced, over time, collective synergy, trust, competence, and interdependence and they were guided to use research results to improve their practice. The BYU Partnership also grappled with issues of power and authority, such as the struggle to widely distribute leadership in an effort to renew school and districts. Differences of viewpoints within the various PLCs were sometimes confounded by a lack of understanding of the shared purposes governing the work, so members responded by educating from within while expanding the membership of targeted stakeholders. Another tension involved the classroom responsibilities of teachers who felt awkward about missing time for instruction. Consensus was sought by creatively accommodating schedules, making compromises, addressing 
misunderstandings, expressing appreciation for differences in roles and viewpoints, and engaging in open, honest dialogue (also see Bullough \& Baugh, 2008).

At the other extreme end of this highly organized model, as captured by the 2009 project, is the Professional Development High School that had met for one academic year in North Carolina to develop its vision. The goals for the PLC network, established in 2007, included creating a school-university PLC collaborative focused on practitioners' professional development and collaboration to improve student learning (Lashley, Cooper, McCall, Yeager, \& Ricci, 2009). For this initiative, university faculty members, a school principal, and curriculum facilitator brought together approximately 65 teachers (representing 10 departments) and 8 cross-campus university faculty (I was one of them) in a newly built high-tech school for which no student population or culture yet existed. All committed in that empty but impressive building to professional learning as a new community of practice that was research based.

A team consisting of practitioners and university faculty created the agenda that embedded the goals of this PLC that had a "blank slate" for planning from the outset. The configuration of the group included preservice teachers whom the PLC teachers and university faculty members wanted to intentionally mentor through group discussion followed by modeling in such forms as supportive co-teaching practices in different content areas. An interview study involving some of the participants surfaced the value placed on building positive school community where all members feel valued and value others through promising practices that include teacher coaching. Recognizing the challenges faced by preservice teachers from the university, beginning teachers in the school, and especially the adolescents who would be entering the school from different backgrounds, motivated the PLC group to create their own school culture. Talking together in a media room, they agreed to build a democratic community for the diverse population of students that signals "a strong sense of purpose and community and high academic expectations" (p. 67). They also agreed that it was important to meet as a group to make visible their commitment to school-university collaboration and peer-led learning.

Such work and commitments make good sense, given that social isolation has reached an epidemic proportion (Putnam, 2000). As communities and teams lost potency in the United States, educators hunkered down, taking to private corners. Because schools and universities show signs of psychological insulation, it is more of a feat than it should be to build organizational capacity through connections and partnerships. Professional isolation is daunting for beginning teachers, especially. In 
isolated rooms, guidance from colleagues is critical. Educators' ability to make a difference grows exponentially when we function as a dynamic social network that values support, engagement, interaction, and transformation (Sergiovanni, 2007; Wenger, 1998).

Arguably, the experience of community has disintegrated over time, and yet practitioners and scholars have reinvigorated the value of community learning through their good work. Structural frames of reference must be bolstered by human frames of reference to avoid isolating people and their work. The metaphor of learning community_or learning landscape-underscores value for social progress through networking, interacting, and bonding. Sergiovanni (1992) encouraged this "paradigm" shift, arguing that "community" (not "organization") is a better way to be thinking about the democratic spaces in which we educate. Thus, it is incumbent upon us to revisit how we think about education; how we interact as leaders and learners; and the models and strategies we create for this purpose. In the 2009 project, we put a human face on the places and spaces where educators collaborate, portraying how at the center of democratic practice are people, relationships, and community, facilitators of which are structures, policies, and agreements that forge a democracy in action (Sergiovanni, 2007).

Working to create social practices supported by vibrant communities, educators enact Sergiovanni's (2007) idea of a "smart school." "Smart learners" teach each other, thereby compounding what they know and are able to do, making "smart schools" a promising practice of change. Where organizational learning of this nature is evident, PLCs have been identified as "smart" cultures (Leithwood, Aitken, \& Jantzi, 2006) within which the social practices of bonding, bridging, and linking occur for school people (Mulford, 2007). As project contributors, we described the "smart" ways that organizations have moved "knowledge into practice" (Schweitzer, Howard, \& Doran, 2008, p. 50), extending the reach of democracies.

Unfortunately, school leaders are often so inundated with survival (in such pressing forms as high-stakes testing, teacher attrition, and daily responsibilities) that they see community and team building as a luxury. Obviously, being transfixed in a survival mode is not a "smart" leadership orientation. Democratic leaders free themselves of the survivalist mindset-they establish the conditions for transforming their workplaces into vital communities of learning wherein members feel motivated to make a difference. They consciously work with others to develop structures that promote synergy and partnership, and sustain the momentum for change in their buildings. How do democratic leaders view their success with developing learning 
communities? Many ironically describe it in measurement terms but nonetheless see it as an indicator of transformational learning through which the social capacity of organizations is increased (English, 2008; Mullen, 2009).

In the 2009 project, we engaged in an educational conversation about community building among different professional groups and within highly varied contexts replete with competing worldviews. Some of us adopted advocacy stances relative to the learning community initiative, others critical, cautionary, and balanced stances, and collectively we addressed organizational, democratic, and leadership issues related to this theme. Together, we presented alternatives to the status quo that makes isolation, as well as individualism and competition feel "natural" and inevitable. We endeavored to help mend the fragmented, dysfunctional state of public schools and rewrite the script of resource-poor, struggling school-communities (Kincheloe, 1999). Although school renewal is in its infancy, we have added to the canon of narrative knowing, living examples of democracy in action (e.g., Clandinin, 2010).

\section{Practical Ideas and Future Directions}

Based on my analysis of the 2009 project and relevant literature, I offer practical ideas and tips for promoting learning community work (see Table 1).

Table 1:

Practical Ideas for Creating Professional Learning Communities

Embrace human | Features of human service organizations include decentralized services structure, diverse, multiple, ambiguous goals, and value-infused lenses. When planning change, consider these and other organizational features. Also, identify your individual and collective assumptions and mindsets; address principles of democracy and learning community and their fit with the vision, mission, and direction of the organization; assess the change and its effect on teaching and the environment; and examine how the proposed change might affect workloads 


\begin{tabular}{l|l}
$\begin{array}{l}\text { Be action } \\
\text { oriented }\end{array}$ & $\begin{array}{l}\text { Develop an action plan that includes such elements as who or } \\
\text { what will be included in the development of the PLC, what } \\
\text { resources are needed for the community initiative (e.g., staff assis- } \\
\text { tance), what professional development supports teacher involve- } \\
\text { ment, and how effectiveness will be assessed }\end{array}$ \\
\hline $\begin{array}{l}\text { Model social } \\
\text { practice }\end{array}$ & $\begin{array}{l}\text { Collaboratively craft your mission and goals; use various types of } \\
\text { data to promote, document, and assess student learning, and } \\
\text { identify leadership practices that foster teacher collaboration and } \\
\text { collective action. Enact democratic decision making to ground } \\
\text { the learning of your community in open and respectful dialogue, } \\
\text { consensus building, and shared leadership }\end{array}$ \\
\hline $\begin{array}{l}\text { Adapt good } \\
\text { ideas }\end{array}$ & $\begin{array}{l}\text { Learn about theories of leadership, community, and change, and } \\
\text { philosophies of education, relevant to your learning community, } \\
\text { in addition to documented practices of educational change. } \\
\text { Adapt what is useful to your context, not as a template but as an } \\
\text { informational source }\end{array}$
\end{tabular}

Encourage new learning
Develop participants as co-leaders and co-learners to reinforce advancements in the culture of teaching. Community-oriented professional development fosters collective identity and a sense of belonging
Forge partnerships
Collaborate with university faculty and school personnel to discuss shared purposes, plan programs, and identify guiding questions. Carry out research focused on school improvement and culturally responsive agendas
Recruit diverse members
Reach inside and outside the organization, including parents, families, students, and teacher candidates/interns. Be mindful of exclusionary practices and cultural expectations. Fully embrace persons of color, community members, and others

\section{Adopt a} mentoring stance
Treat differences in age, generation, gender, leadership style, etcetera as a strength and resource for mentors and learners. Avoid relying solely on mentoring programs to foster professional learning — support professionals' individual and varying needs to maximize outcomes 
Communicate electronically
Digital systems and VLCs can advance one's vision, mission, and goals. These allow for experimentation with the more traditional form of PLCs and, at their best, promote the creation of new democratic spaces, increased political participation, synergistic (reciprocal and collegial) interactions, and group identity development

Make activities challenging
With participants (via workshops, courses, other), identify barriers that people encounter and action steps for generating solutions. Do activities that move participants outside their comfort zones (e.g., simulations, debates) focused on goals (e.g., making schools culturally engaging places to work)

The collective learning of schools depends on the willingness and expertise of their faculties to adopt expanded definitions of learning community, leadership, and governance. Educators who support democratic practices of community and who dialogue across cultural differences help meet organizational goals in previously unrealized ways. Leaders who work effectively together are reciprocal partners who support school/district/state initiatives through goal setting, collaborative problem solving, and inquiry projects and through such outcomes as content creation, program development, and student success. PLC members who purposefully set in motion positive change engage new ways of being within their learning community landscapes. They build social capacity, develop social identity, and impact their communities.

Future directions for creating learning communities and researching them can address many challenging areas of professional life. These include micropolitics, external factors and pressures, toxic culture, and consensus building. A recent study that addresses these educational issues is Whitford and Wood's (2010) 6-year examination of seven school districts. Information from teachers who belonged to PLCs in Florida, New Jersey, New Mexico, Pennsylvania, and Washington was analyzed. The PLC founders, serving as the research team, addressed both pros and cons of this complex work. As a pro, like the PLC contributors to the 2009 Mullen project, the 2010 PLC teachers shared that positive collaboration and meaningful conversation among stakeholders was a major benefit. As a con, Whitford and Wood also found that PLCs introduced difficult problems that took time away from teaching; however, practitioners liked having the opportunity to identify their own issues and seek solutions as a team. 
Readers may find the wide-ranging PLC portrait I have presented useful for forging ahead with their own democratically oriented communities. As part of this portrait, I have compiled practical ideas from my own readings and experiences that provide orientations and steps for creating PLCs (see Table 1). It takes time and patience to do PLC work for which synergistic learning communities become the process and product of change. More and more PLCs are translating research results into promising practices, creating policies through consensus, and integrating digital communications. In our work lives, many of us see democracy in action. However modest the signs may seem, synergy builds synergy and cultures change.

\section{References}

Birchak, B., Connor, C., Crawford, K. M., Kahn, L. H., Kaser, S., Turner, S., et al. (1998). Teacher study groups: Building community through dialogue and reflection. Urbana, IL: National Council of Teachers of English.

Bullough, R. V., \& Baugh, S. C. (2008). Building professional learning communities within a university-public school partnership. Theory Into Practice, 47(4), 286-293.

Bullough, R. V., \& Baugh, S. C. (2009). Developing professional learning communities in a university-public school partnership. In C. A. Mullen (Ed.), The handbook of leadership and professional learning communities (pp. 39-49). New York: Palgrave Macmillan.

Cernohous, S., Wolsey, T. D., \& Grisham, D. L. (2010). Contemporary technological innovations in teaching and learning and teacher education. Teacher Education Quarterly, 38(1). Retrieved July 25, 2010, from http://teqjournal.org/editors.html

Clandinin, D. J. (2010). Narrative understandings of lives lived in and out of schools. LEARNing Landscapes, 3(2), 15-20.

Cooper, C.W. (2009). Performing cultural work in demographically changing schools: Implications for expanding transformative leadership frameworks. Educational Administration Quarterly, 45(5), 694-724.
Davis, D. J. (2008). Mentorship of a sharecropper's daughter: Being young, gifted, and Black in academe. In C. A. Mullen (Ed.), The handbook of formal mentoring in higher education: A case study approach (pp. 73-83). Norwood, MA: Christopher-Gordon.

Donahoo, S., \& Hunter, R. C. (Eds.). (2007). Teaching leaders to lead teachers: Educational administration in the era of constant crisis, vol. 10. Oxford, UK: Elsevier Science.

DuFour, R. (2004). Schools as learning communities. Educational Leadership, 61(8), 6-11.

English, F.W. (2008). The art of educational leadership: Balancing performance and accountability. Thousand Oaks, CA: SAGE.

Fives, H., Buehl, M. M., \& Myers, S. D. (2008). The cultivation of a professional associationbased new faculty mentoring program. In C. A. Mullen (Ed.), The handbook of formal mentoring in higher education: A case study approach (pp. 165-190). Norwood, MA: Christopher-Gordon.

Giroux, H. A. (1992). Educational leadership and the crisis of democratic government. Educational Researcher, 21(4), 4-11.

Gladwell, M. (2002). The tipping point: How little things can make a big difference. New York: Little, Brown, and Company. 
Jenlink, P. M., \& Jenlink, K. E. (2008). Creating democratic learning communities: Transformative work as spatial practice. Theory Into Practice, 47(4), 311-317.

Johnson, B. L., \& Kruse, S. (2009). Decision making for educational leaders: Under-examined dimensions and issues. New York: SUNY.

Kincheloe, J.L. (1999). How do we tell the workers? The socioeconomic foundations of work and vocational education. Boulder, CO: Westview.

Lashley, C., Cooper, J., McCall, J., Yeager, J., \& Ricci, C. (2009). Teacher education is everybody's business: Northern Guilford High Schoola professional development community. In C. A. Mullen (Ed.), The handbook of leadership and professional learning communities (pp. 59-71). New York: Palgrave Macmillan.

Leithwood, K. A., Aitken, R., \& Jantzi, D. (2006). Making schools smarter: A system for monitoring school and district progress (3rd ed.). Thousand Oaks, CA: Corwin.

Lewis, D., \& Allan, B. (2005). Virtual learning communities: A guide for practitioners. England, UK: Open University Press.

McKenzie, K. B., Cambron-McCabe, N., Capper, C. A., Christman, D. E., Dantey, M., Gonzalez, M. L., et al. (2008). From the field: A proposal for educating leaders for social justice. Educational Administration Quarterly, 44(1), 111-138.

Mulford, B. (2007). Building social capital in professional learning communities: Importance, challenges and a way forward. In L. Stoll \& K. Seashore Louis (Eds.), Professional learning communities: Divergence, depth and dilemmas (pp. 166-180). London: Open University Press.

Mullen, C. A. (Ed.). (2009). The handbook of leadership and professional learning communities. New York: Palgrave Macmillan.

Mullen, C. A. (2011). Renewing professional organizations and action learning. Action Learning: Research and Practice, 8(2), 149157.
Mullen, C. A., \& Hutinger, J. L. (2008). The principal's role in fostering collaborative learning communities through faculty study group development. Theory Into Practice, 47(4), 276-285.

Mullen, C. A., \& Schunk, D. H. (2010). A view of professional learning communities through three frames: Leadership, organization, and culture. McGill Journal of Education, 45(2), 185-203. Retrieved March 6, 2011, from http://mje.mcgill.ca

Putnam, R. D. (2000). Bowling alone: The collapse and revival of American community. New York: Simon and Schuster.

Rogers, J. (2000). Communities of practice: A framework for fostering coherence in virtual learning communities. Educational Technology \& Society, 3(3), 384-392.

Schweitzer, L., Howard, E. J., \& Doran, I. (2008). Planners learning and creating power: A community of practice approach. Journal of Planning Education and Research, 28(1), 50-60.

Sergiovanni, T.J.(1992). Moral leadership: Getting to the heart of school improvement. San Francisco: Jossey-Bass.

Sergiovanni, T. J. (2007). Rethinking leadership: A collection of articles ( $2^{\text {nd }}$ ed.). Thousand Oaks: Corwin.

Shields, C. M., \& Mohan, E. J. (2008). High-quality education for all students: Putting social justice at its heart. Teacher Development, 12(4), 289-300.

Watts, I. E., \& Erevelles, N. (2004). These deadly times: Reconceptualizing school violence by using critical race theory and disability studies. American Educational Research Journal, 41(2), 271-299.

Wenger, E. (1998). Communities of practice: Learning, meaning, and identity. Cambridge, UK: Cambridge University Press.

Whitford, B. L., \& Wood, D. R. (Eds.). (2010). Teachers learning in community: Realities and possibilities. New York: SUNY.

Zhao, C-M, \& Kuh, G. D. (2004). Adding value: Learning communities and student engagement. Research in Higher Education, 45(2), 115-138. 


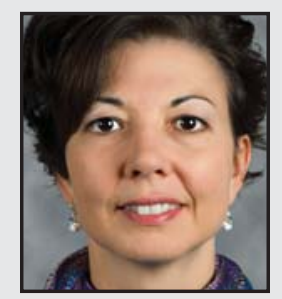

Carol A. Mullen, PhD, is Professor and Chair, Educational Leadership and Cultural Foundations Department, The University of North Carolina at Greensboro. She specializes in social justice approaches to leadership mentoring in education. She is long-time, former editor of the Mentoring \& Tutoring journal (Routledge). She has published 15 books and also edited The Handbook of Leadership and Professional Learning Communities (2009, Palgrave Macmillan).

\section{LINK TO:}

www.uncg.edu/ camullen 